\title{
Airways obstruction, coal mining, and disability
}

\author{
N L Lapp, W K C Morgan, G Zaldivar
}

\begin{abstract}
It has recently been suggested that the inhalation of coal in the absence of complicated coal workers' pneumoconiosis (CWP) or smoking can lead to disabling airways obstruction. The cause of such obstruction has been variously attributed to emphysema or bronchitis. The frequency of significant airways obstruction in a group of United States coal miners seeking compensation for occupationally induced pulmonary impairment was therefore determined. In a sample of 611 "Black Lung" claimants there was only one subject who was a non-smoker and who in the absence of other non-occupationally related diseases,-for example, asthma and bronchiectasis-had sufficient airways obstruction to render it difficult for him to carry out hard labour. An alternative explanation for his reduced ventilatory capacity other than coal dust or smoking may be available. If the inhalation of coal dust in the absence of smoking and complicated CWP ever induces sufficient ventilatory impairment to preclude a miner from working, it is indeed rare.
\end{abstract}

(Occup Environ Med 1994;51:234-238)

The prolonged inhalation of coal mine dust may lead to three lung conditions-namely, coal workers' pneumoconiosis (CWP), silicosis, and industrial bronchitis. ${ }^{12}$ Silicosis is uncommon and occurs only in roof bolters and those employed in transportation. Coal workers' pneumoconiosis is divided into simple and complicated forms with the first being recognised in life by a lengthy history of exposure to coal mine dust and the presence of small rounded opacities on the chest radiograph. Complicated pneumoconiosis occurs on the background of simple CWP and is characterised by the development of one or more large opacities greater than $1 \mathrm{~cm}$ in diameter. Whereas it is generally agreed that simple CWP has no effect on life expectancy, the higher stages of complicated CWP are associated with significant impairment and in some instances premature death. ${ }^{2}$ Industrial bronchitis is a non-specific response that occurs in any subject who has a lengthy and heavy exposure to particles of dust that are deposited mainly in the airways and whereas CWP and industrial bronchitis are often associated, the bronchitis often occurs in the absence of CWP or other pneumoconioses. ${ }^{23}$ There is compelling evidence to indicate that in some subjects industrial bronchitis is associated with slight airways obstruction. ${ }^{34}$

For several years there has been a debate as to whether the long continued inhalation of coal dust in the absence of complicated CWP can lead to the development of significant and disabling airflow obstruction and if so by what means. ${ }^{56}$ For the most part when severe obstruction is found in a coal miner he virtually always is or has been a cigarette smoker, or failing that has complicated CWP. Rarely other coincidental diseases that are unrelated to occupation may cause obstruction-for example, bronchiolitis, bronchiectasis, and asthma. Some investigators claim that severe obstruction may uncommonly occur in nonsmoking miners and that when present it is due to emphysema that has been induced by the inhalation of coal dust rather than cigarette smoke. ${ }^{5-7}$ We therefore decided to ascertain how often significant airways obstruction was found in non-smoking coal miners without progressive massive fibrosis but who were seeking compensation for "Black Lung".

Subjects and methods

All subjects were working, retired, or deceased United States coal miners. Either the miner or the nearest surviving relative, usually the spouse, had filed a claim for Black Lung benefits with the US Department of Labor (DOL) or with the Social Security Administration (SSA). Around $25 \%$ of the claimants had been referred to the University of West Virginia Medical Centre by the DOL or SSA. A further $20 \%$ had been referred to one of us (GZ). The remainder of the medical data, and in particular, chest radiographs and lung function tests, had been sent to one or more of us for interpretation and review. In many instances complete hospital outpatient and inpatient records were available, some dating back 30 or more years. In the case of a deceased miner, hospital records, his chest radiographs, spirometric tracings, and blood gas analyses, if available, along with postmortem findings and a copy of his death certificate were forwarded to us for comment. In around $50 \%$ of subjects we had been asked to review the medical data by the legal representatives of the coal companies that had employed the miner. Many had been previously examined by one or other of us for the DOL. A few subjects had been referred by a

Road, London, Winderme

Canada N6A 5A5.

Accepted for publication 9 August 1993 
State Workmens' Compensation Board. In some instances (about 10\%) the subject had been seen and examined by one or more of us on two occasions.

Ninety eight per cent of the subjects referred to us had chest radiographs performed at some time in their lives and in most instances at least one was available. A few exceptions were men who had died suddenly and in whom there was no record of a chest radiograph having been taken. The number of radiographs available ranged from one to over 30 , although it was customary to rely on the $x$ ray films taken in the immediate period before the miner filed his claim. In some instances the chest radiographs spanned 20 years or more. Because of the extreme variability in the interpretation of chest radiographs in subjects claiming Black Lung benefits, and the fact that some approved readers invariably read every claimant's film as positive, only those interpretations originating from a cadre of readers were accepted. The cadre was mainly drawn from the radiology departments of the Johns Hopkins Hospital, the University of Cincinnati, and the University of Southern California. Most of these radiologists had been consultants to the US Public Health Service or to the DOL. Also, a few chest physicians and radiologists who had acted as consultants to the US Public Health Service or to other governmental agencies were included. In total, there were 16 readers, all of whom had passed the $B$ reader examination conducted by the National Institute of Occupational Safety and Health (NIOSH) and the American College of Radiology. ${ }^{8}$ This tests the proficiency of the candidate's ability to classify the chest radiographs of an occupational population according to the International Labour Office Classification of the Pneumoconioses. Agreement as to the presence or absence of CWP between at least two or more of the readers from the selected group was necessary before a radiographic diagnosis of CWP was accepted.

Many subjects had multiple sets of spirometric tracings available, in some instances up to eight, and a similar number of blood gas determinations. Ventilatory capacity was assessed on a large number of different spirometers of which around $60 \%$ of those identified met the NIOSH criteria for accuracy and acceptability. ${ }^{9}$ Values varied immensely in the same subject, often over a short period. Validity was based on fulfillment of the American Thoracic Society (ATS) criteria for acceptability. ${ }^{10}$ Only when valid spirometric data were available was pulmonary impairment diagnosed. Fortunately, as mentioned, most subjects had undergone spirometry on multiple occasions and in most subjects at least one set of valid results was available. A clinically significant reduction of the ventilatory capacity was present when the forced expiratory volume in one second $\left(F_{1}\right)$, the forced expiratory volume (FVC), or the ratio of the $\mathrm{FEV}_{1}$ to the FVC $\left(\mathrm{FEV}_{1} /\right.$ FVC\%) was $60 \%$ or less. ${ }^{11}$

\section{Results}

There were 611 claimants. Of this total there were 411 smokers or ex-smokers, 37 nonsmokers, and 163 for whom the smoking history was not available. The greatest number of cigarettes to which the claimant admitted smoking was accepted as the most realistic index as it was considered that few, if any, subjects would inflate their consumption. Many of the subjects in whom no smoking history was available had died suddenly and had subsequently had a postmortem examination carried out. Of those who had a smoking history taken on one or more occasions, $41 \%$ had a consistent smoking history. In $15 \%$ of miners who admitted smoking at one time either they or their surviving family subsequently maintained that they were lifelong non-smokers. A further $25 \%$ of subjects who were smokers underestimated their consumption by $5 \%$ to $50 \%$, and $19 \%$ of the smokers underestimated the number of cigarettes smoked on at least one or more occasions by more than $50 \%$. Of 25 subjects whose carboxyhaemoglobin concentration had been recorded at the time of the examination, and who said that they had given up smoking completely, nine had carboxyhaemoglobin values above $5 \%$. In most instances the subject being tested had been in the pulmonary function laboratory or in the physician's office for at least an hour or often two hours before determination of the carboxyhaemoglobin content.

The mean number of chest radiographs in those who had been examined during life was $5 \cdot 2$. In many instances 10 or more interpreters had been involved in reading the various chest radiographs. Thus the number of interpretations per claimant was about 15 . Similarly, spirometry had usually been performed on the average about six times per subject; however, a few had had their ventilatory capacity assessed for compensation purposes on up to 16 separate occasions, sometimes over a period of 15 or more years. Likewise, multiple blood gas determinations were carried out with the mean number of determinations being just over three. Around $10 \%$ of live claimants did not have blood gas determinations, however.

There were six non-smoking subjects with a clinically significant reduction of their ventilatory capacity as defined earlier. Of these six subjects, three had asthma, one of whom underwent repeat testing and was subsequently found to have normal values while in remission. A further subject had fibrosing alveolitis and another had bronchiectasis. One non-smoker had an $\mathrm{FEV}_{1} / \mathrm{FVC}$ ratio of $55 \%$, although his $\mathrm{FEV}_{1}$ was just over $60 \%$. No definite explanation for his obstruction could be determined from his medical records and the question as to whether dust exposure itself was likely to have caused the disease was considered. He had worked for a short time only at the coal face, although he had worked underground. His chest radiograph did not show CWP. Of those whose smoking history was not known, 16 fulfilled 
Table 1 Prevalence of radiological CWP* and of significant pulmonary impairment according to smoking habit where known in those examined during life

\begin{tabular}{lcclcc}
\hline & $\begin{array}{l}\text { No of } \\
\text { subjects }\end{array}$ & $\begin{array}{l}\text { Radiological } \\
\text { CWP }\end{array}$ & $\begin{array}{l}\text { No } \\
\text { radiological } \\
\text { CWP }\end{array}$ & $\begin{array}{l}F E V_{1} \text { or } \\
F E V, / F V C \\
<60\end{array}$ & $\begin{array}{l}\text { Other non-dust } \\
\text { related } \\
\text { airways disease }\end{array}$ \\
\hline $\begin{array}{l}\text { Non-smokers (n) } \\
\begin{array}{c}\text { Smokers and } \\
\text { ex-smokers (n) }\end{array}\end{array}$ & 31 & 4 & 27 & 6 & 5 \\
$\begin{array}{l}\text { Smoking history } \\
\text { unknown (n) }\end{array}$ & 147 & 30 & 327 & 154 & 7 \\
Total (n) & 531 & 19 & 124 & 16 & 11 \\
\hline
\end{tabular}

*Thirty two per cent of those with category $1 / 0$ or greater had irregular opacities reported as present on their chest radiograph. the criteria. In 11 of the 16 an adequate explanation for the reduced ventilatory capacity was available from their medical recordsnamely, fibrothorax, interstitial fibrosis, lung resection, etc. Of the remaining five, none had CWP. In the smokers slightly over $30 \%$ of those with reliable spirometric data met the criteria. Table 1 shows this relation of smoking to the prevalence of CWP as diagnosed by chest radiography and significant pulmonary impairment. Thirty two per cent of those with category $1 / 0$ or greater had irregular opacities reported as present in their chest radiograph. As such, these opacities are not related to the coal content of the lung but to other factors. ${ }^{12}$

Of the group of 611 subjects who either made a claim themselves or for whom a claim was rendered, 80 had died. Table 2 lists the various conditions found during life and at death. In many instances, more than one morbid condition was present during life or at death. Thus coal workers' pneumoconiosis, heart disease, and emphysema were frequently associated. Similarly, lung cancer and emphysema frequently coexisted. For this reason the total diseases found under the column at death add up to more than the number of subjects who underwent a complete or partial postmortem examination. In no instance was there a non-smoker who died from emphysema or cor pulmonale and the only non-smoking subject who died of a lung condition had interstitial fibrosis (fibrosing alveolitis).

Table 2 Diseases identified in 611 claimants

\begin{tabular}{|c|c|c|}
\hline & While alive* & At death ${ }^{*}$ (80 subjects) \\
\hline CWP & 53 (all simple) & 12 (necropsy, all simple) \\
\hline $\begin{array}{l}\text { Other lung conditions } \\
\text { (emphysema, bronchiectasis, } \\
\text { bronchitis, and pulmonary fibrosis) }\end{array}$ & 120 & 46 (15 diagnosed during life) \\
\hline Asthma & 15 & - \\
\hline $\begin{array}{l}\text { Heart disease } \\
\quad \text { (including stroke) }\end{array}$ & 167 & 49 \\
\hline Obesity & 80 & - \\
\hline Lung cancer & 21 & 14 \\
\hline $\begin{array}{l}\text { Other cancers } \\
\text { (including myeloma, lymphoma, } \\
\text { and leukaemia) }\end{array}$ & 27 & 7 \\
\hline $\begin{array}{l}\text { Sundry causes of death or } \\
\text { other diseases found at necropsy } \\
\text { (including trauma) }\end{array}$ & - & 18 \\
\hline $\begin{array}{l}\text { Skeletal problems } \\
\text { (including arthritis) }\end{array}$ & 53 & 7 \\
\hline $\begin{array}{l}\text { Normal or with other conditions but } \\
\text { no CWP or abnormalities of lung } \\
\text { function }\end{array}$ & 144 & - \\
\hline
\end{tabular}

*More than one condition often present in the same subject.
Heart disease and stroke were often found and usually associated with obesity and cigarette smoking. Under the heading sundry causes of death and other diseases found at death, a variety of conditions was noted, including a few deaths from trauma. There were 144 subjects who were examined and found to have no discernible disease likely to cause chest symptoms or who had a normal ventilatory capacity and blood gases.

\section{Discussion}

The group of subjects included in our study does not reflect the health state of United States coal miners as a whole. Thus it could be suggested that the selection of disability claimants introduces bias and we agree with this. None the less, if airways obstruction induced by coal dust occurs in non-smoking coal miners in the absence of complicated CWP, then it is likely that there would be an increased frequency of airways obstruction in the population we studied in view of the fact that over $99 \%$ professed shortness of breath. Moreover, other investigators have inferred that coal mine dust may induce disabling airways obstruction in similar but even more highly selected populations. ${ }^{6713}$ Thus Hurley and Soutar selected 199 men from an original population of 17738 coal miners. ${ }^{7}$ These subjects were said to have a more severe inverse relation between exposure to coal dust and $\mathrm{FEV}_{1}$ than was expected; however, of the 199 only $11(6 \%)$ were said to be nonsmokers. Errors are not infrequent in smoking histories, as is evident from this paper, and also in a prior British publication. ${ }^{14}$ Some of the 11 non-smokers may have smoked at sometime in their lives. Also, perhaps the airways obstruction in Hurley and Soutar's nonsmoking subjects could have been explained by asthma, bronchiectasis, or some other cause of chronic airflow limitation not related to dust. Keeping these facts in mind it is undoubtedly evident, even in the subjects of Hurley and Soutar ${ }^{7}$ that the main cause of airways obstruction is cigarette smoking rather than dust.

All but one of the claimants in our study professed respiratory symptoms and the solitary exception had been told to apply for Black Lung benefits by a lawyer. Many had serious and life threatening diseases, hardly any of which were related to inhalation of coal dust. Only 65 of the 611 claimants (10.6\%) had CWP, this being around the same frequency of coal workers' pneumoconiosis noted in Appalachian miners between 1960 and $1970 .{ }^{14}$ As expected, most subjects claiming disability were older men but none had complicated CWP, presumably because the presence of CWP automatically qualifies the applicant for benefits for total and permanent disability from the Department of Labor.

Of those whose smoking history was known, 411 of the $448(91 \%)$ were smokers or ex-smokers. The average percentage of smokers and ex-smokers in the United States 
working population at the present time is around $40 \%$; however, around $60 \%$ to $65 \%$ of United States coal miners were smokers in the late 1960 s and early 1970 s. ${ }^{15} 16$ In a substantial number of subjects there was no smoking history or it was not recorded. Some subjects had died abruptly and undergone a postmortem examination to ascertain whether CWP was present and as a result no smoking history was available. The excessively high frequency of cigarette smoking in the group would explain the high prevalence of heart disease and chronic airflow limitation. By contrast the relative rarity of significant chronic airflow limitation in non-smokers is very obvious. Only one non-smoking subject had significant obstruction for which no obvious explanation was apparent. The obstruction, however, was not severe and would not qualify him for SSA or DOL benefits. He had not been seen or examined by any of us and his medical history was incomplete. Although he had no radiographic evidence of CWP, it was possible that he may have had a previous attack of bronchiolitis or could have had bronchiectasis, or there may have been some other explanation for his airflow limitation.

In those for whom a smoking history was not available, there were five subjects who had significant obstruction according to the given criteria. None of these had CWP. All five of those with significant airways obstruction may have been smokers but there was no indication that this was so from the scanty records of these subjects.

Seaton has suggested that the inhalation of coal dust in the absence of cigarette smoking or of complicated CWP may cause significant airways obstruction by inducing centriacinar, or as it is sometimes called, centrilobular emphysema. ${ }^{6}$ We accept that coal miners have an excess of emphysema over and above that seen in the general population. This was shown by Gough and Heppleston many years ago, ${ }^{17} 18$ and has subsequently been confirmed by the US Public Health Service studies which showed that simple CWP in nonsmokers was associated with an increase in the residual volume and total lung capacity and in some instances with a slight to moderate loss of elastic recoil. ${ }^{19} 20$ Furthermore, Hankinson and colleagues, who were working in the Appalachian Laboratory for Occupational Lung Disease (ALFORD) at the same time showed that simple CWP was associated with an increase in air space size. ${ }^{21}$ These workers were, however, unable to demonstrate that the increased size was associated with a reduction in ventilatory capacity. Although the increase in residual volume that is found in non-smoking coal miners with and without simple CWP can be explained by the presence of industrial bronchitis, the bronchitis cannot explain the increase in total lung capacity that was found in smoking coal miners. ${ }^{4}$ The increased total lung capacity must be a consequence of the fact that there is a decreased elastic recoil of the lungs.

There is little doubt that cumulative exposure to respirable coal mine dust is associated with a greater prevalence of both CWP and of fibrosis, and that the severity of the fibrosis is related to the category of simple CWP. Similarly we accept that the higher the category of simple CWP, the more extensive is the emphysema. We differ, however, with Seaton when he goes on to infer that the emphysema that may be present of necessity causes the airways obstruction, which may affect both smoking and non-smoking miners. ${ }^{6}$ Were this the case the $\mathrm{FEV}_{1}$ should decrease as the category of simple CWP increases in the same manner as the residual volume and total lung capacity increase with increasing category of CWP. It has been shown repeatedly, however, that the $\mathrm{FEV}_{1}$ is not affected by increasing category of simple CWP. ${ }^{20}$ By contrast, the extent of emphysema induced by cigarette smokers in both miners and non-miners is clearly related to the decrement in $\mathrm{FEV}_{1}$, and to the increment in residual volume and total lung cancer. ${ }^{415192022}$ Others argue that because there is a decrement in the $\mathrm{FEV}_{1}$ that is related to lifetime dust exposure and also to the extent of any emphysema present, it is reasonable to infer that there is a cause and effect relation between the decrement in $F_{1} V_{1}$ and the extent of centracinar emphysema. ${ }^{67}$ Seaton suggests that it is plausible for the decline in $\mathrm{FEV}_{1}$ to be related to emphysema and that the emphysema must be caused, at least in part, by exposure to coal dust. ${ }^{6}$ In smoking miners, as dust exposure increases, so also does cigarette smoking and the two are collinearly related. Seaton relies on a report by Ruckley et $a l^{23}$ to support his view, but the data in the report do not seem to support his contention. Ruckley et al describe 257 miners who underwent postmortem examination, some of whom had respiratory function tests carried out in life. ${ }^{23}$ Not all of the 257 miners had pulmonary function tests within the last five years of life, however, and thus many were excluded. Of the 257 miners, there were only two nonsmokers who had emphysema in the absence of $C W P$. The extent of the emphysema in these two subjects was not mentioned, but the authors state in their methods that they accepted the presence of significant emphysema when it had affected as little as 1/30th of the lung. As such, this would include many subjects who had emphysema with no functional significance and no symptoms as usually at least $20 \%$ to $30 \%$ involvement is necessary before symptoms occur. ${ }^{22} 24$ The authors also state that emphysema was uncommon in non-smokers younger than age 65 unless they had progressive massive fibrosis. They go on to state that "this suggests that non-smokers with the highest lifetime exposures at British collieries have a lower risk of developing centriacinar emphysema than a smoker with a minimal dust exposure." They also argue that bronchitis is not responsible for the decrement in $\mathrm{FEV}_{1}$ that occurs in coal miners as compared with other occupations and quote Fletcher et $a l^{22}$ in support of their view that the investigations of 
these workers showed that air flow obstruction and mucus hypersecretion were largely independent processes, and that mucus hypersecretion was not associated with significant airways obstruction. In the next paragraph, however, Ruckley et al indicate that the Reid Index, the best measure of the severity of the bronchitis, in their series was particularly associated with a reduction in the $\mathrm{FEV}_{1}$ as also was the $\mathrm{FEV}_{1} / \mathrm{FVC} \%{ }^{23}$ They then inferred that the increased Reid Index might reflect a disturbance in the larger airways, something that we had suggested many years previously. ${ }^{34}$ It is abundantly clear, from both our findings in the present study of disability claimants, and from the findings of Ruckley et $a l^{23}$ that significant airways obstruction is indeed rare in coal miners in the absence of progressive massive fibrosis or cigarette smoking. This is borne out in a study of working United States coal miners that included 9076 subjects from 31 mines and 10 states. $^{25}$ In the subjects who were over the age of 50 , and in whom the prevalence of CWP and airways obstruction was greatest, $20 \%$ met the existing Department of Labor disability criteria and $25 \cdot 3 \%$ of a similar non-mining population met the standard. Since that time the criteria for total disability have been made significantly more stringent.

One of the unfortunate consequences of the Federal Black Lung Acts has been to add to the cost of Appalachian coal. This along with other factors has led to a situation in which coal can no longer compete with oil. These various additional costs have contributed to the closure of something like $60 \%$ of the coal mines in Appalachia with an equivalent massive reduction in the work force. Finally, if, as we believe, the claimants whom we studied or whose records we reviewed constitute a reasonably representative sample of Black Lung claimants, then it follows for the most part that the impairment and disability found in those claiming Black Lung benefits have a non-occupational origin, and as such they should be compensated but in the same manner as are similarly disabled non-miners.

This work was supported in part by the University Hospital Foundation.
1 Morgan WKC, Lapp NL. State of the art. Respiratory disease in coal miners. Am Rev Respir Dis 1976;113: 531-59.

2 Morgan WKC. Coal workers' pneumoconiosis. In: Morgan WKC, Seaton A, eds. Occupational lung diseases. 2nd ed. Philadelphia: WB Saunders, 1984:337-449.

3 Morgan WKC. Industrial bronchitis. $\mathrm{Br} F$ Ind Med 1978; 35:185-91.

4 Hankinson JL, Reger RB, Morgan WKC. Maximal expiratory flows in coal miners. Am Rev Respir Dis 1977; 116:175-80.

5 Marine WM, Gurr D, Jacobsen M. Clinically important respiratory effects of dust exposure and smoking in British coal miners. Am Rev Respir Dis 1988;137:106-12.

6 Seaton A. Coal mining, emphysema, and compensation. Br F Ind Med 1990;47:433.

7 Hurley JF, Soutar CA. Can exposure to coal mine dust cause a severe impairment of lung function? $\mathrm{Br} \mathcal{F}$ Ind Med 1986;43:150-7.

8 Morgan R. Proficiency examination of physicians for classifying pneumoconiosis chest films. American fournal of Roentgenology, Radium Therapy and Nuclear Medicine 1979;132:803.

9 ATS Statement Snowbird Workshop on standardization of spirometry. Am Rev Respir Dis 1979;119:831-8.

10 ATS standardization of spirometry. 1987 Update. Am Rev Respir Dis 1987;136:1285-98.

11 Morris JF, Koski A, Johnson LC. Spirometric standards for healthy nonsmoking adults. Am Rev Respir Dis 1971;103:57-67.

12 Dick JA, Morgan WKC, Muir DFC, Reger RB, Sargent $\mathrm{N}$. The significance of irregular opacities on the chest roentgenogram. Chest 1992;102:251-60.

13 Cockcroft AE, Wagner JC, Seal RME, et al. Irregular opacities in coal workers pneumoconiosis: correlation with pulmonary function and pathology. Ann Occup Hyg with pulmonary

14 Collins HPR, Dick JA, Bennett JG, et al. Irregularly shaped small shadows in chest radiographs, dust exposure and lung function in coal workers' pneumoconiosis. $\mathrm{Br}$ F Ind Med 1988;45:43-55.

15 Lainhart WS, Doyle HM, Enterline PE, et al. Pneumoconiosis in Appalachian bituminous coal miners. Washington, DC: US Department of Health, Education and Welfare Government Printing Office, 1962.

16 Kibelstis JA, Morgan EJ, Reger RB, et al. Prevalence of bronchitis and airways obstruction in American bituminous coal miners. Am Rev Respir Dis 1973;108:886-93.

17 Gough J. The pathogenesis of emphysema. In: Liebow A, Smith DE, eds. The lung. Chapter 9. Baltimore: Williams and Wilkins, 1968.

18 Heppleston AG. The pathogenesis of simple pneumoconiosis in coal workers. $\mathcal{f}$ Pathol Bact 1954;67:51-63.

19 Morgan WKC, Burgess DB, Lapp NL, et al. Hyperinflation of the lungs in coal miners. Thorax 1971;26:585-90.

20 Morgan WKC, Handelsman L, Kibelstis $\mathrm{J}$ et al. Ventilatory capacity and lung volumes of US coal miners. Arch Environ Health 1974;28:182-9.

21 Hankinson JL, Palmes ED, Lapp NL. Pulmonary air space size in coal miners. Am Rev Respir Dis 1979; 119:391-7.

22 Fletcher CM, Peto R, Tinker E, Speizer FE. The natural history of chronic bronchitis and emphysema. New York: Oxford Univ Press, 1976:129-32.

23 Ruckley VA, Fernie JM, Campbell SJ, et al. A clinicopathological study of emphysema, airways obstruction and pathological study of emphysema, arways obstruction and massive fibrosis. Edinburgh: Institute of

24 Ryder RC, Dunnill MS, Anderson JA. A quantitative study of bronchial mucous gland volume, emphysema, and smoking in a necropsy population. 7 Pathol Bact and smoking in

25 Morgan WKC, Reger RB, Handelsman L. Black lung benefits. $\mathcal{F} A M A$ 1973;233:922. 